\title{
Respiratory failure after thoracoplasty: treatment by intermittent negative-pressure ventilation
}

\author{
EH SAWICKA, MA BRANTHWAITE, GT SPENCER \\ From the Department of Thoracic Medicine, Brompton Hospital, and Department of Anaesthesia, \\ St Thomas's Hospital, London
}

ABSTRACT Ten patients with severe respiratory failure secondary to extensive pulmonary tuberculosis and thoracoplasty have been treated with intermittent negative-pressure ventilation. All recovered and have been followed up for from six months to eight years. Two have died from unrelated causes and six have used some form of breathing aid at home. Negative-pressure ventilation, which is a non-invasive form of respiratory support, offers important benefits in selected cases.

Thoracoplasty played an important part in the management of pulmonary tuberculosis before the advent of effective chemotherapy. In 1947 Holmes Sellors reported a series of 633 patients operated on between 1935 and $1946^{1}$ and the work potential of about two-thirds of the 588 who had been traced was regarded as normal. In a later series from the same centre, Gough et $a l^{2}$ described the outcome in 231 patients followed after thoracoplasty for six to eight years. Again the results were good but four late postoperative deaths were attributed to cor pulmonale. Pulmonary fibrosis and thoracic cage deformity caused by tuberculosis and thoracoplasty were considered to have contributed to these deaths, although a history of chronic bronchitis with emphysema was noted in all four and tuberculosis was quiescent at death in only two. Since then, chest wall deformity combined with extensive and often bilateral pulmonary fibrosis has been recognised more widely as a cause of respiratory failure and cor pulmonale, often presenting many years after the thoracoplasty. We report here a series of 10 such patients, whose cardiorespiratory failure proved refractory to conventional treatment and who were managed by intermittent negative-pressure ventilation.

\section{Patients and methods}

The group consists of seven women and three men, whose ages at thoracoplasty and at presentation in

Address for reprint requests: Dr M Branthwaite, Brompton Hospital, London SW3 6HP.

Accepted 2 February 1983 cardiorespiratory failure are shown in the table. The vital capacity measurements carried out after treatment with negative-pressure ventilation and expressed as a percentage of the mean predicted figure $^{3}$ give some indication of the extent of respiratory impairment. Considerably lower figures were obtained in those patients able to perform the forced expiratory manoeuvre before treatment.

The thoracoplasty removed at least five ribs in all but two patients; right upper lobectomy and limited thoracoplasty had been performed in one case, and the final patient had had a four-rib thoracoplasty but no resection. Details of other treatment for tuberculosis were scanty but all had had a phrenic crush, artificial pneumothorax, or other collapse procedure on the side of the thoracoplasty and several had had an artificial pneumothorax maintained for some time on the opposite side. The patient treated by four-rib thoracoplasty on the left had also had a right oleothorax, which caused very extensive pleural thickening. All patients had radiological evidence of healed tuberculosis, the non-operated as well as the operated side being extensively affected in six cases and part of the non-operated side being affected in all.

At presentation there were two smokers, four life-long non-smokers, and four ex-smokers. Four patients were considered on grounds of their history to suffer from chronic bronchitis (cough and daily sputum production for some years) and four had evidence of ischaemic heart disease. Five patients had been leading normal lives until a few weeks or months before the acute deterioration which precipitated the need for ventilatory support, but the 
Clinical details of the 10 patients

\begin{tabular}{|c|c|c|c|c|c|c|c|c|c|c|}
\hline $\begin{array}{l}\text { Sex and age at presentation } \\
\text { Age at thoracoplasty } \\
\text { History of chronic bronchitis } \\
\text { Previous IPPV } \\
\text { VC after recovery (\% predicted) }\end{array}$ & $\begin{array}{l}\text { M } 58 \\
36 \\
\text { Yes } \\
\text { Yes } \\
38\end{array}$ & $\begin{array}{l}\text { M } 57 \\
33 \\
\text { Yes } \\
\text { Yes } \\
57\end{array}$ & $\begin{array}{l}\text { M } 59 \\
35 \\
\text { Yes } \\
62\end{array}$ & $\begin{array}{l}\text { F } 55 \\
26\end{array}$ & $\begin{array}{l}\text { F } 52 \\
25 \\
\text { Yes } \\
32\end{array}$ & $\begin{array}{l}F 62 \\
33\end{array}$ & $\begin{array}{l}\text { F } 52 \\
20 \\
\text { Yes } \\
31\end{array}$ & $\begin{array}{l}\text { F } 68 \\
30 \\
\text { Yes }\end{array}$ & $\begin{array}{l}\text { F } 68 \\
26 \\
29\end{array}$ & $\begin{array}{l}\text { F } 66 \\
24 \\
\text { Yes } \\
35\end{array}$ \\
\hline $\begin{array}{l}\text { Duration of follow-up (y) } \\
\text { Events during follow-up }\end{array}$ & D & $>5$ & & 3 & & * & D & $\dagger$ & & \\
\hline
\end{tabular}

IPPV - intermittent positive pressure ventilation; VC-vital capacity; D-death during follow-up from non-respiratory cause.

* Patient has carcinoma of pancreas; no respiratory symptoms.

† Patient lost to follow-up but is reported to be well.

other five had been too disabled to work or had led restricted lives for some years. Four patients were referred because intermittent positive-pressure ventilation had been instituted elsewhere for lifethreatening respiratory failure and it had proved impossible to restore spontaneous ventilation. One patient who had recovered after a period of positive-pressure ventilation was transferred because his condition remained poor and was deteriorating again. The remaining five patients were in severe respiratory failure, with arterial carbon dioxide tensions $\left(\mathrm{PaCO}_{2}\right)$ of $63-82 \mathrm{~mm} \mathrm{Hg} \mathrm{(8.5-}$ $11.0 \mathrm{kPa})$ and cor pulmonale at the time of presentation, had failed to respond to conventional treatment, and were considered to be within hours or days of death.

Intermittent negative-pressure ventilation was established using either a Cape Alligator $^{4}$ or Kelleher $^{5}$ rotating tank ventilator operating at a negative pressure of $20-40 \mathrm{~cm} \mathrm{H} O$. These machines are both cabinet (tank) ventilators designed in two sections hinged together at one end. The patient's head is supported on an adjustable rest outside the cabinet and a soft rubber collar completes the seal around the body. The cabinet is mounted in a frame which has an adjustable pivot so that the long axis of the cabinet can be tilted between $10^{\circ}$ head up and $25^{\circ}$ head down. The Kelleher model differs from the simpler Alligator because the frame forms a cradle in which the entire cabinet and head rest can be rotated through $180^{\circ}$ so that the patient, supported by a light-weight padded frame within the cabinet, can be turned into the prone position.

Treatment could be interrupted for short periods for nursing procedures and meals, either from the outset or within a few days of admission. Physiotherapy to aid the elimination of secretions was continued either by rotating the patient for drainage in the Kelleher ventilator or by conventional techniques. Intermittent arterial blood gas analysis was used to follow the gradual restoration of normal oxygen and carbon dioxide tensions, and oxygen supplements were given through nasal cannulas to patients who remained hypoxaemic while ventilated with air.

\section{Results}

Although conscious patients expressed some reluctance to enter the "iron lung," they soon appreciated the relief of dyspnoea and most slept within an hour or two. No sedation was required to facilitate synchronisation of spontaneous respiratory effort with the machine, and successful extubation was possible immediately in those intubated on arrival. There were no adverse cardiovascular consequences and diuresis was established within 12 hours in all patients.

Once normal or near-normal arterial blood gas tensions and $\mathrm{pH}$ had been achieved while ventilation was supported mechanically the patient was allowed to spend longer and longer periods breathing spontaneously. Assistance at night was continued for a few more days until there was little diurnal variation in arterial blood gas values. The total period of treatment varied from two to six weeks and the duration of follow-up has ranged from six months to more than eight years.

Readmission for further treatment has been necessary in eight patients, either to arrest gradual deterioration or to provide respiratory support during. a respiratory tract infection. Six patients use some form of respiratory assistance at home (table). This takes the form of either a cuirass ${ }^{6}$ or tank ventilator, used intermittently and only at night, or short periods (5-10 minutes) of positive-pressure breathing during the day using a Cape TC50 portable ventilator (Cape Warwick Ltd, Warwick). This is a volume preset, time-cycled, positive-pressure device which can be set to deliver a tidal volume equal to or a little greater than the patient's unaided vital capacity. The quality of life has been improved for all patients, although those disabled for more than a year before admission continue to lead restricted lives. Two patients have died during follow-up, both from causes unrelated to their pulmonary disease.

\section{Discussion}

Endotracheal intubation and intermittent positive- 
pressure ventilation are used to treat a small proportion of patients with acute or acute-on-chronic respiratory failure. ${ }^{78}$ The results are best in those with a reversible condition such as severe acute asthma, whereas the mortality is higher in those with chronic disease, particularly when the immediate cause of deterioration is trivial and is superimposed on a considerable degree of disability. ${ }^{7}$ The adverse prognosis in this group can be attributed in part to the complications of treatment-in particular, the need for sedation to relieve the discomfort of endotracheal intubation, hypotension and a reduction in cadiac output when positive-pressure ventilation is established, an increased incidence of pneumonia and pneumothorax, disorders of the gastrointestinal tract, and above all difficulty in restoring spontaneous ventilation and achieving successful extubation.

Once initiated, intermittent positive-pressure ventilation cannot be interrupted or withdrawn prematurely. Understandably, therefore, aggressive treatment is often withheld in all but the most favourable cases. By these criteria, the patients in this group would be considered unsuitable for intubation and positive-pressure ventilation, and indeed it was the failure to restore spontaneous ventilation in four who had been treated in this way that prompted a trial of an alternative technique.

Cabinet respirators, capable of providing ventilation by applying a negative pressure to the trunk, have fallen into disuse during the last 20 years. They do, however, offer a number of advantages in selected cases. There is no need for sedation to relieve discomfort or diminish spontaneous respiratory effort, there is no interference with feeding, patients can receive and communicate with their visitors, treatment does not predispose to the development of pulmonary complications such as infection or pneumothorax, and it can be interrupted for short periods without ill effect. In the patients we report here negative-pressure ventilation was successful and devoid of complications in all cases and none of those requiring further periods of treatment expressed any reluctance or distaste.

Although it is easy to understand that relief of arterial hypoxaemia, improved elimination of carbon dioxide, and cessation of the work of breathing all contribute to immediate improvement, it is more difficult to understand how the benefit has been sustained. The ventilatory response to an increase in arterial carbon dioxide tension will be improved once the biochemistry of the blood and cerebrospinal fluid has been restored to normal, ${ }^{9}$ and eliminating the sleep deprivation which often accompanies respiratory insufficiency may also enhance ventilatory drive. ${ }^{1011}$ Right ventricular function will improve when the pulmonary vascular resistance is lowered by relief of hypoxia and acidosis; and possibly mechanical ventilation helps to restore mobility of the chest wall, so lessening the work of breathing.

Several patients have been maintained in good health by the use of some form of respiratory assistance at home, although the nature of any benefit provided in this way is obscure. Alleviating respiratory muscle fatigue and preventing or minimising deterioration of arterial blood gas tensions during sleep $^{12}$ may contribute; alternatively, improvement in lung compliance sustained for some hours after a period of forcible hyperinflation may diminish the work of breathing and improve gas exchange. ${ }^{13}$ Further work is needed to determine whether prolonged mechanical assistance to respiration is beneficial and, if so, when it should be used.

\section{References}

${ }^{1}$ Holmes Sellors T. The results of thoracoplasty in pulmonary tuberculosis. Thorax 1947;2:216-23.

${ }^{2}$ Gough JH, Barlow D, Holmes Sellors T, Thompson VC. The results of thoracoplasty in the treatment of pulmonary tuberculosis. Thorax 1957;12:241-52.

${ }^{3}$ Cotes JE. Lung function: assessment and application in medicine. 4th ed. Oxford: Blackwell Scientific Publications, 1979.

${ }^{4}$ Galpine JF. A new cabinet respirator. Lancet 1954;i:707-9.

${ }^{5}$ Kelleher WH. A new pattern of iron lung for the prevention and treatment of airway complications in paralytic disease. Lancet 1961;ii:1113-6.

${ }^{6}$ Spencer GT. Respiratory insufficiency in scoliosis: clinical management and home care. In: Zorab PA, ed. Scoliosis. London: Academic Press, 1977:315-28.

${ }^{7}$ Petheram IS, Branthwaite MA. Mechanical ventilation for pulmonary disease: a six year survey. Anaesthesia 1980;35:467-73.

${ }^{8}$ Nunn JF, Milledge JS, Singaraya J. Survival of patients ventilated in an intensive therapy unit. $\mathrm{Br}$ Med J 1979;i:1525-7.

${ }^{9}$ Fencl V, Vale JR, Broch JA. Respiration and cerebral blood flow in metabolic acidosis and alkalosis in humans. J Appl Physiol 1969;27:67-76.

${ }^{10}$ Douglas NJ, White DP, Weil JV, Pickett CK, Zwillich CW. Overnight sleep deprivation decreases ventilatory drive. Thorax 1982;37:791 (abstract).

${ }^{11}$ Cooper KR, Phillips BA. Effect of short-term sleep loss on breathing. J Appl Physiol 1982;53:855-8.

12 Douglas NJ, White DP, Pickett CK, Weil JV, Zwillich $\mathrm{CW}$. Respiration during sleep in normal man. Thorax 1982;37:840-4.

${ }^{13}$ Sinha R, Bergofsky EH. Prolonged alteration of lung mechanics in kyphoscoliosis by positive pressure hyperinflation. Am Rev Respir Dis 1972;106:47-57. 